\title{
Ondes de Kelvin-Helmholtz
}

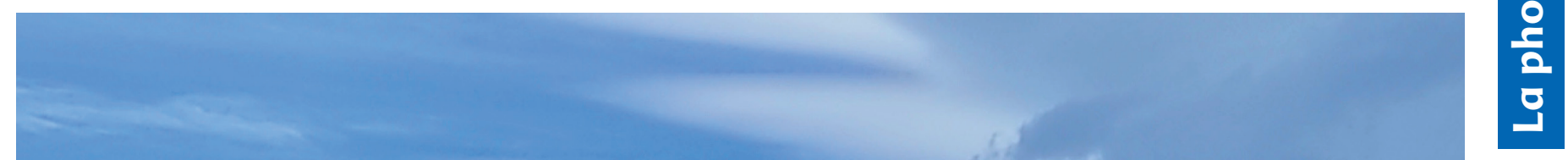

Photo prise sur le plateau du Coscione (Corse-du-Sud) le 7 mai 2021 à $11 \mathrm{~h}$.

Crédit : Dominique Lambert, Laboratoire d'aérologie, Université de Toulouse 3.

e libeccio est un vent violent de secteur ouest à sud-ouest qui traverse la Corse.

Il concerne plus particulièrement les extrémités nord et sud de l'île, s'accompagnant de rafales pouvant atteindre les $200 \mathrm{~km} / \mathrm{h}$ ! Ici, sous des conditions moins sévères, un épisode de libeccio a touché la Corse le 7 mai 2021. II est à l'origine de ce nuage en forme de vagues (fluctus selon l'appellation de l'Atlas international des nuages) qui traduit le phénomène d'ondes de Kelvin-Helmholtz. Ces ondes apparaissent dans une masse d'air stable en présence d'un fort cisaillement de vent vertical entre deux couches. Le vent plus fort dans la couche supérieure crée une instabilité et, si la masse d'air est suffisamment humide, les ondes sont matérialisées par ces nuages typiques. Les ondes de Kelvin-Helmholtz sont plus fréquentes dans des régions au relief tourmenté qui perturbe l'écoulement. 


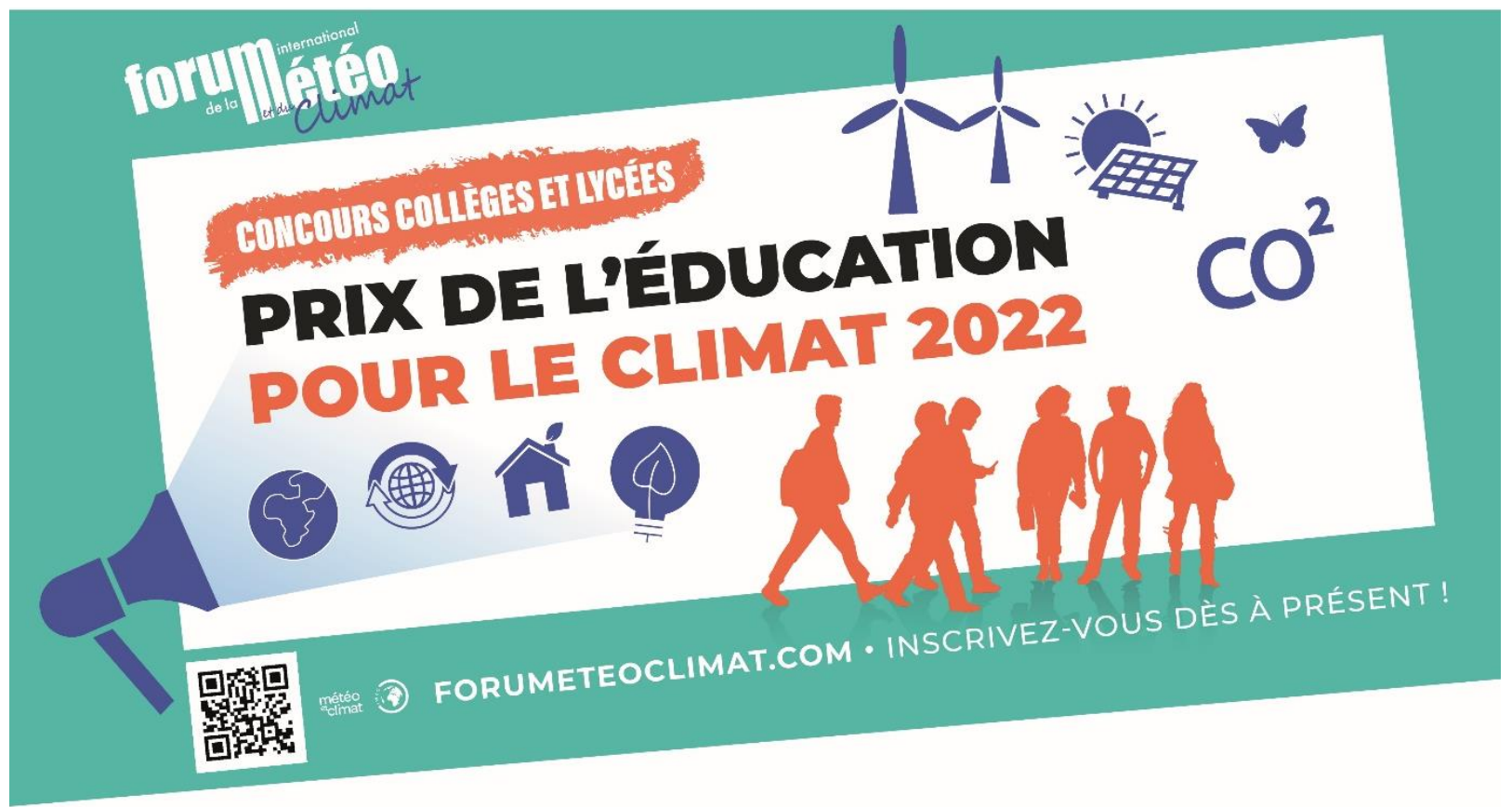

\section{À PROPOS}

Le Prix de l'Éducation pour le Climat 2022 est organisé dans le cadre du Forum International de la Météo et du Climat.

II s'adresse aux classes de collèges et de lycées qui réalisent au cours de l'année scolaire 2021-2022 un projet pédagogique sur les thèmes de la météorologie, du climat, de l'environnement ou du développement durable. Ce prix valorise l'implication des élèves dans des projets pédagogiques autour des enjeux climatiques.

\section{DATES-CLÉS POUR CONCOURIR?}

1) Confirmez votre intention de candidature en vous inscrivant avant le 18 mars 2022 sur le site du Forum (forumeteoclimat.com).

2) Déposez votre projet entre le 18 mars et le 8 avril 2022 pour participer à la phase de pré-sélection.

3) Après le 8 avril 2022, le jury procédera à l'examen des candidatures et désignera les 5 meilleurs projets qui participeront à la finale en mai 2022 sur le parvis de l'Hôtel de Paris, dans le cadre du $19^{\mathrm{e}}$ FIM.

\section{CRITÈRES D'APPRÉCIATION}

Les projets seront évalués par un jury composé de scientifiques et d'acteurs éducatifs selon les critères suivants:

- Démarche "éducation à l'environnement et au développement durable",

- Implication des élèves dans le projet,

- Pertinence des supports fournis.

\section{PARTICIPATION À LA FINALE DE MAI 2022}

Si votre projet est présélectionné, il devra être abouti d'ici mai 2022 pour pouvoir être présenté par les élèves devant le jury lors de la finale.

En savoir plus sur le prix de l'éducation pour le climat:

https://forumeteoclimat.com/scolaires/prix-de-leducation-pour-le-climat-2022 